\title{
To the End: Exposing the Absolute
}

"Toute infinité requiert une errance."

"The task is indeed to demonstrate what the absolute is. But this demonstration cannot be either a determining or an external reflection by virtue of which determinations of the absolute would result, but is rather the exposition of the absolute."

“Notez que je suis absolument immanentiste.”3

\section{Introduction}

The Immanence of Truths is the vineyard in which all the labour of the reader of the first two Being and Event volumes finally, and one might dare to say, absolutely pays off. And - as in the famous Jesus parable - those who start with the last volume will receive just as much as those who started years and years ago. Everyone will have received the same currency, notably orientation - and especially a reader of Badiou's last systematic volume is enabled to see what has any real value - and this means "absolute value."' For this reason alone, time does not matter much for the currency that the absolute provides us, as it is that "which in time exceeds time." 5 Yet, the peculiar place where this absolute value system is formulated is difficult to locate. It is close by, ${ }^{6}$ yet and at the same time it does not exist in any standard sense of the term. The place of the absolute is

Alain Badiou, L'Immanence des vérités. L'Être et l'événement, 3, Fayard, Paris,2018, p. 236.

G. W. F. Hegel, Science of Logic, Cambridge University Press, Cambridge 2010, p. 466.

3 Alain Badiou, "L'être en nombres", in Entretien 1. 1981-1996, Nous, Paris 2011, p. 177.

4 Badiou, L'Immanence des vérités, p. 417.

5 Ibid., p. 176.

6 Cf. Frank Ruda, “Tovariši absoluta, ali: Kje je ‘auprès de nous?”, in Problemi, (3-4/2019), pp. 133-150. 
like an invisible, inexistent, yet under certain conditions universally accessible Fort Knox for the people, that is: for everyone.

In what follows I will take a field trip into this inexistent yet rigid fort of the absolute. To do so, I will: 1. elucidate the specific perspective of Being and Event, 3 against the background of the two previous volumes; and 2. I will turn to the immanent but invisible dialectic of the general floorplan of the absolute fort that Badiou calls absolute ontology and offer a reading thereof. This will lead to a discussion (albeit limited) of the place "where all possible forms of" infinite "multiples" 7 are located, and will show in what sense it provides us with a means to "measure" a truth's inner infinity, i.e. the absoluteness of a truth. The article will end by only pointing in the direction of what deserves further elaboration in the future, namely the conceptual requirement needed to conceive, metaphorically speaking, of the unfolding of the inner inconsistency of the (concept of the) absolute. How to form a (philosophical) concept (the absolute) which is barely still a concept due to the "absolute powderiness" that follows from the "intrinsic diversity of [the] types of infinity"10 that inhabit it? That the absolute, "the absolute referent [...] in-exists" ${ }^{11}$ and nonetheless provides an - in this sense fictional ${ }^{12}$ - orientational measure can be understood, as will be shown, against the background of an impossible yet necessary (i.e. forced) totalisation of the domain of the absolute. The article will signal that at the abyssal ground as well as at the impossible end of the absolute there is a paradoxical experience of freedom.

$7 \quad$ Badiou, L'Immanence des vérités, p. 245.

8 Ibid., p. 333. Previously, it seemed that what Badiou called "nature," the ordered sequence of ordinals, could provide such a measure. "Nature, even infinite, is absolute," as he stated. Alain Badiou, Being and Event, Continuum, London / New York, 2006, p. 362. Now, the set of ordinals only provides us with an internal model, an attribute of the absolute, as there are not only ordinals in the latter. Cf. Badiou, L'Immanence des vérités, pp. $371 \mathrm{ff}$.

9 Badiou, “L'entretien de Bruxelles”, in Entretien, p. 107.

10 Badiou, L'Immanence des vérités, p. 374.

${ }_{11} \quad$ Ibid., p. 417.

12 What precisely this kind of fiction is will become clearer in what follows. But it should be clear that it is not meant to be a mere construct of language or discourse. Cf. ibid., p. 30. Badiou once linked it to the idea that a truth is always related to what it will have been (and due to this specific temporality has a fictitious being). Cf. Alain Badiou, "Philosophie \& Politique”, in Entretiens, p. 132. 
This is just the roadmap or, if the reader prefers, the activity plan for the envisaged field trip. I take it that such a roadmap or activity plan (or both) can help when one seeks to exit from whatever cave one comes from (for example, one's preconceptions of what the infinite is, or what one believes Badiou is doing anything that can actually work as a cave, and hold us hostage). It is mainly supposed to enable one to not lose the way on the way (out). ${ }^{13}$

\section{From the being of truths to their appearing...}

The Immanence of Truth is not a book that addresses the universality of truth nor its singularity but its absoluteness. ${ }^{14}$ It therefore does not deal with the concept of the generic (set) that elucidates a truth's universality nor with that of the inexistent of a world from which its concrete singularity can be accounted for. It deals with the inner link between truth and the absolute and thereby with that of truth and the infinite..$^{15}$ The genuine perspective of The Immanence of Truth can best be established by depicting why such an absolute point of view is at all systematically necessary. ${ }^{16}$ This is especially significant since it is, which for the average professional philosopher will sound irritating, a(n impossible) "view from nowhere." ${ }^{{ }_{17}}$ But one should recall that "absoluteness" ${ }^{18}$ already played an obvious role in Being and Event, 1 and therefore Badiou's entire philosophical project seems to depend on how pertinent the perspective of Vol. 3 will prove to be.

13 Badiou claims that The Immanence of Truths depicts the cave (of finitude), leads us out of it (so that we encounter the blinding brightness of the different sizes of infinities in the absolute, i.e. a heaven of ideas). It then makes us return to the cave, so that we are able to make a difference (between waste [déchet] and work [oeuvre]). Badiou not only depicts the constitution of the (ontological) cave - which surprisingly disappears if we have a different orientation - but a philosopher is also he or she who, by confronting us with the absolute, drags us out of it: because one should remember that the prisoners do not want to leave voluntarily.

14 Badiou, L'Immanence des vérités, p. 275. Absoluteness also necessitates addressing the dialectic between the finite and the infinite. Cf. Alain Badiou, Le fini et l'infini, Bayard Culture, Paris, 2010.

15 This is already the gesture of Cantor, whose "ontological thesis is evidently that inconsistency [...] orientates thought towards the Infinite as supreme-being, or absolute.” Cf. Alain Badiou, Being and Event, Bloomsbury, London / New York, 2013, p. 42.

16 Badiou himself raised this question: "But what is the general necessity for a third book?" Cf. Alain Badiou, “Conférence de Ljubljana”, in Filozofski Vestnik, 32 (2/2011), p. 7.

${ }_{17}$ Thomas Nagel, A View from Nowhere, Oxford University Press, Oxford 1986.

18 Cf. appendix 5 in Badiou, Being and Event, pp. $456 \mathrm{ff}$. 
What thus is the systematic need for a third volume? If it is systematically necessary, this necessity must derive from the specific gaps left by the first two instalments of Being and Event. These gaps do not turn their respective enterprises into flawed or failed ones. The point is not that they lack something that could have been done better. Rather, their respective perspectives, when taken together, enable us to see that something is missing (from their points of view), which only appears to be missing because of their points of view. Only after Being and Event and Logics of Worlds are we enabled to see that something is missing. So, what they brought to the fore was a systematic lack: a lack that only exists because they did what they did. After they established and achieved what they set out to do, it became evident that they only determined in a negative manner what necessarily also needs a positive elaboration. What is it that we only get a negative rendering of? Both books depicted only negatively what it means for a truth to emerge in a historically specific situated world as a set of consequences of an event. They did not positively deliver a demonstration of why and in what sense a thusly produced truth can actually be said to be (eternally) true.

Badiou always argued that "each truth is, in a sense, absolute," 19 but the first two books did not tell us too much about the inherent conception of the absoluteness of truths. Rather, they did account for it in oppositional terms. This is a systematic implication of their perspective, since they did not positively begin from (within) the (immanence of the) absolute or infinite and then derive an account, for example, of the finite from it. They all argued for a need to think the infinite, yet did not conceive of it from within the immanence of a truth's inner unfolding, even if they relied on what specific generic processes made it possible to think..$^{20}$ But Badiou had to reverse the perspective: a(n almost Platonic) turn was needed. ${ }^{21}$ To understand the precise coordinates of this turn, one may ask again: Why did the first two volumes of the Being and Event series not de-

19 Alain Badiou and Maria Kakogianni, Entretien Platonicien, Lignes, Paris 2014, p. 52.

20 In some sense, my rendering is imprecise and rather heuristic. Because already for Being and Event, 1 it is clear that it is the infinite that "carries or bears the finite, a truth that carries a subject." Alain Badiou, "Beyond Formalization. An Interview”, in Angelaki. Journal of the Theoretical Humanities, Vol. 8, No. 2, August 2003, p. 132. And equipped with an adequate concept of infinity, we can see that "the infinite, only the infinite testifies for the truths.” Badiou, L'Immanence des vérités, p. 419.

${ }_{21}$ On this motive, cf. Frank Ruda, "Marx in the Cave”, in Slavoj Žižek, Frank Ruda, Agon Hamza, Reading Marx, Polity, London 2018, pp. 62-100. 
liver everything one needed to conceive of the (non-)relation between its main terms, being and event? Was this not what they set out to do?

An answer to this question can be sketched out if we recall the previous books' achievements in slightly greater detail. Being and Event articulated Badiou's meta-ontological concept of being - meta-ontological because, mind you, philosophy is "not [...] ontology." ${ }^{22}$ It did so by identifying mathematics, i.e. axiomatised set-theory with the discourse of ontology. In the same book, Badiou conceptualised how such a philosophical meta-ontology allows the conception of an event, i.e. of 'something' which is not really some thing and which therefore is not what an ontology can possibly account for. It cannot do so, because if an event really is an event, it is not derivable from being (ontologically formalised) qua being. ${ }^{23}$ This yields an important consequence for the overall systematic perspective of this volume and the whole project: events can happen even within ontology - as discourse on being. Ontology - but not being! - has a history, because its very concept of being can be transformed. ${ }^{24}$

The concept of the event and that which is directly linked to it, i.e. the concept of truth, was therefore determined in the first volume of Being and Event in a primarily negative or at least supplementary way. It was the "and", or as Badiou himself phrased it in almost deconstructive language, it was conceived as what "supplements" 25 being. In Being and Event, we start from being and get to that

22 Badiou, Being and Event, p. 3. This is the case, since "ontology [...] exists as a separate and exact discipline," i.e. mathematics.

23 For this, ibid., pp. 184-190. If it were derivable from a given concept of being, it could be described by recourse to "the encyclopaedia of the situation" (ibid., pp. $327 \mathrm{ff}$.) and hence could be constructed by recourse to the already existing language (which conceptually means there could never be any evental supplement to being, everything would already be latently there and hence the book series could have been called simply Being). Ibid., pp. 265-327. This problem will acquire a new dramatic form in The Immanence of Truths.

24 Being and Event philosophically deploys the conceptual consequences of the "Cohenevent," as something that happened - contingently - in and to ontology. Ibid., p. 16. Yet if what 'substantiates' an event is what will have followed from it, there are therefore also necessarily ontological truths: This is why "there is a history of mathematical truths." Alain Badiou, "Dix-neuf réponses à beaucoup plus d’objections”, in Entretiens, 1: 19811996, Nous, Paris 2011, p. 67.

25 This is why any generic procedure - that "practice" which produces the consequences of an event and thus makes the event into what it will have been - that is inaugurated by an event can be described as an "undecidable supplement” (Badiou, Being and Event, p. 355), 
which is not being. That-which-"is-not-being-qua-being" ${ }^{26}$ proved to be as important as that-which-is (being). Therefore, in a dialectical move, we need to say something about the being of that which is not being-qua-being and thereby we say something about (the being of) truth. Its primary characterisation was negative in the sense that it was doubly derived from the meta-ontological perspective on being: when a truth has originated in what is not-being-qua-being (an event), the being of this truth is - as also holds true for everything that is also a type of multiple (even though a specific, generic one). Being and Event proposed "a complex thinking of the being of truths." ${ }_{27}$

The "impossible possibility" 28 of truths arises from what is not (being qua being) - and it is not, because it happens. After determining what is constitutive of truths, one is able to determine them as that which also and necessarily transforms that which is (even being qua being). So, we move from being to that which is not-being to that which results from the latter and transforms the former. Truths thus bring temporalisation (and history) to being - being, this was Badiou's anti-romantic (anti-Heideggerian) wager, ${ }^{29}$ has no history of its own. A historicising truth is therefore always a non-derivable, aleatory supplement to being. History is aleatory and alethic time. Being and Event presents a number of concepts for grasping post-evental truths: the event, elucidating its "origin," the "generic" which determined the being of a truth, the concept of "fidelity" (describing its practical aspect) and the concept of "forcing" that determines "truth as truth," ${ }^{\circ}$ i.e. the being of truth in general. Being and Event says something about being and it elaborates what Badiou once called the subjective process, but it does not give us all the conceptual tools needed to think subjectivisation

which is itself sustained by a further, additional, or supplementary supplement, namely "the fiction of a theory" (ibid., p. 246), the "supplementary hypothesis" (ibid., p. 249) of assuming the totalisation and closure of a generic procedure (as in saying: "I will always love you" after falling in love due to encountering someone new). This is a simplified rendering of forcing.

26 Ibid., 15.

27 Badiou, “Dix-neuf réponses”, p. 65.

28 Alain Badiou, Can Politics Be Thought?, Duke University Press, Durham / London 2019, p. 97.

${ }_{29}$ The project is a "de-romanticization of the infinite." Cf. Badiou, "L'être en nombres", p. 189.

30 Badiou, “Dix-neuf réponses”, p. 65. 
proper. ${ }^{31}$ Even though the concept of forcing - allowing one to conceive of the functioning of the "subject-language," ${ }^{2}$ i.e. of the interiority of an engaged subjective perspective and the immanent representation of what a subject believes it is doing - and Badiou's overall philosophy can already here be convincingly described as "genericism," 33 the event and all related concepts were elucidated against the backdrop of being.

Logics of Worlds, the second volume of Being and Event, changes the perspective. It does not deal with being as such but with (formalising) all the possible ways in which (something of) being can appear. Everything that is can appear when it is localised in a determined logical space, in a world. Logics of Worlds thus presents a meta-phenomenology where phenomenology, the logic of appearance proper, is related to mathematical algebra and topology. ${ }^{34}$ Different from traditional phenomenology, the meta-phenomenological perspective elides all references to an already given subject of (potential) experience. The book elaborated a non-subjective theory of the transcendental, 35 of that which governs the laws of appearance of a singular world. All appearances of being are worldly and thus historical. ${ }^{36} \mathrm{And}$ even though being appears, appearance has its own logics roughly put: logic is to appearance what mathematics is to being. Its exposition leads to an account of the multiplicity of different worlds and the different forms

${ }^{31}$ For this distinction, which Badiou himself uses (cf. Badiou, “Conférence”, p. 15): Alain Badiou, Theory of the Subject, Continuum, London/New York 2009, pp. 241-275.

32 Badiou, Being and Event, p. 40of.

33 Badiou, "Philosophie \& Politique", in Entretiens, p. 136.

34 Alain Badiou, Logics of Worlds, Being and Event, 2, Continuum, London / New York 2009, p. 234 .

35 Ibid., pp. 97-188.

36 A reader of Logics of Worlds might be surprised that within the logics of appearance certain crucial concepts of the meta-ontological account seem to have disappeared (or been forgotten). But this can mostly be easily explained: What happened to the distinction between nature and history that was crucial for Being and Event? The explanation is obvious: whatever appears appears according to transcendentally governed laws; and even if the most stable form of multiplicities (nature) appears, it appears in a particular setting. Their ontological structure will not be transformed by their appearance (there can be factual changes to a natural world through evolution, for example - and factual changes are not events, which means that there are still no events in nature). But nature meta-ontologically, as physis, is obviously quite different from phenomenal nature. 
of appearance within the frame of an "objective phenomenology." ${ }^{37}$ This objective meta-phenomenology, to state the obvious, is not meta-ontology: it deals with a realm of its own in which (something of) being appears in the form of bodies that are accompanied by their respective languages or descriptions. ${ }^{38}$

This is the backdrop against which Logics of Worlds seeks to elucidate the appearance of what constitutes a truth and the appearance thereof. We thus get in this work also a theory of all the possible ways in which change can appear, the most intense being an event (pun intended). And we also get an account of the ways in which a post-evental truth-practice can appear ${ }^{39}$ and of the appearance of a subject, of a subjective body - since true change that appears also appears as a body..$^{40}$ The appearance of an event is related - note the structural repetition to that which in appearance does not appear, to that which appears so minimally that it appears not to appear, to what appears to "inexist" 4 in a world. An event effectively allows for a change in the laws of appearance, a change of the transcendental..$^{42}$ It makes exist that which inexisted by presenting a momentary suspension of the transcendental (which is therefore an appearance of disappearance) that consequently effectuates a transformation of its laws. Logics of Worlds accounts for this transformation by offering an account of what it means for a truth to appear within a concrete and particular world. Badiou thus accounted for the appearance of a truth by recourse to that which is not (because it happens, even to and in appearance).

37 Badiou, Logics of Worlds, pp. 277-280. Surprisingly enough, Thomas Nagel used the same term to describe his own, quite different project. Cf. Thomas Nagel, "What Is It Like to Be a Bat?", in The Philosophical Review, 83, (4/1974), p. 449.

${ }^{38}$ Badiou, Logics of Worlds, pp. 191-296. On the meta-ontological level, this is referred to as the "language of the situation" (Badiou, Being and Event, p. 288f).

39 Meta-ontologically speaking, all elements of an evental situation can only refer in a positive or negative way to the event (when examined); meta-phenomenologically speaking, worlds know more variety, which is why Badiou here also must say something about the reactive and obscure subject (when elaborating what a truth-practice looks like).

$4^{0}$ Technically speaking: it is that whose identity with an event is maximal. Cf. Alain Badiou, Le séminaire - Images du temps présent: 2001-2004, Fayard, Paris 2014, p. 422.

${ }_{41}$ Badiou, Logics of Worlds, pp. 321-324 and pp. 376-378. There is only one inexistent in a world and it is therefore the point on which the whole consistency of the world hinges and which singularises it.

42 Not all transformations affect the transcendental of a world, but an event does. For a catalogue of the different types of change, ibid., p. 374. 
A truth appears when something appears, as a consequence of an event, which did not appear (and thus did not seem to exist or be possible) before. This conversion appears in the form of a new body that is engaged in a practice of phenomenal self-organisation or auto-transcendentalisation (a classical name for it is freedom). To account for how the product of an event within a world is able to suspend the transcendental and to itself take charge of the laws of appearance, Badiou develops a theory of the subjectivisable body. All that appears in a world are bodies and languages, except when truths appear. They appear as a different type of body, as truth-bodies. They are not simply finite, but inscribe something else into the apparently closed universe of a world. Logics of Worlds demonstrates that a subject is not only structured like a language, but also like a dialectic, ${ }^{43}$ because within it infinity (truth) and finitude (every body is finite) are materially woven together in a truth-body that appears in a particular world. A subjectivised truth-body inscribes the infinite into a world - because it takes decisions what path to take, what type of consequences to explore, with whom to ally itself, etc., and these decisions are crucial not only for the body's continued existence, i.e. the "bodily [en-corps]" 44 materialisation of a truth's self-organisation, but also for the transformation of a world. These decisions are what Logics of Worlds refers to as points and they are how the infinite is "filtered by the form of the two," "\$5 i.e. by the form of a decision (of how to continue) into the world (again: we are here talking about freedom). ${ }^{46}$ Being and Event, 2 says something about (the) appearance (of being) and it elaborates conceptual tools to account for the appearance of subjective truth-bodies. But it does not give us an account of what subjectivation looks like from the perspective of an individual who incorporates him- or herself into an active truth-body - surprisingly for many of its readers, forcing does not play a very explicit role in it. Even though the complex dialectic of the infinite and the finite is clearly at the centre of Badiou's account of the truth-body, its constitution and transformation, the

43 Cf. Alain Badiou, Le séminaire - L’un: Descartes, Platon, Kant (1983-1984), Fayard, Paris 2016, p. 141.

44 Badiou, Logics of Worlds, p. 46.

45 A point is always the infinite treated in the form of the two. Cf. Badiou, Images du temps présent, p. 384.

46 It should be clear that inscribing the infinite into the finite by forcing it into the form of the two of an either-or choice means that the infinite (of any truth) is closely linked to freedom. This is an implication that comes fully to the fore in The Immanence of Truths. I will return to this point (pun again intended) below. 
event and all related concepts, especially that of truth, were elucidated against the backdrop and within the frame of the logics of appearance.

\section{... to their immanence}

Two books, two accounts of eventally originating truths, none of which would put truth first. With the third and final volume, the turn must thus be made: truth first! Before we can see what this entails, it is worth pointing out a peculiar problem that arose with and from the publication of Badiou's Logics of Worlds. The problem can be described in the following simple way: What is the relation between Vols. 1 and 2 of Being and Event? Obviously, one deals with being, the other with appearance, and both deal with the respective relation to eventally originating truths. But is there anything that necessitated the appearance of being? If so, one would have to explain the origin of appearance outside of appearance (notably in being). This runs counter to the concept of being that Being and Event elaborates. Nothing in being drives being to appear. For in itself being is static. Therefore, the appearance of being cannot be derived from the concept of being. But why then is there appearance - is this a supplement to being (and what kind)? Is this just contingent?

This set of questions is further complicated by the fact that ontology (as mathematics) clearly appears and hence its world - since "ontology is a situation"47 follows specific, transcendental, laws ${ }^{48}$ that govern what can appear and what cannot appear within it. ${ }^{49}$ Here, it is again important to recall that ontology is

47 Badiou, Being and Event, p. 27.

${ }^{48}$ Badiou, Logics of Worlds, pp. 183ff. This can mean that there is not first being and "then" also appearance, but that it is as plausible to speak of a primacy of appearing, since it is only within the appearing discourse of ontology, mathematics, that we - if we attempt to identify what it is doing from a meta-ontological position - formulate a concept of being. In this sense, Badiou systematically avoids a two-layer model of ontology and phenomenology.

49 Ibid., pp. 183-188. The following should be noted: 1. that ontology as such does not have a concept of the event - the event is a meta-ontological, i.e. philosophical concept. Which means "the event" appears as inexistent in the classical world of ontology. 2. It is here important to note that mathematics comes first (as ontology) and logics comes second (as phenomenology). Badiou himself worked in the 1960s within the framework of a "mathematicised logics," a "logical materialism" in which "the difference between a mathematical theory and a logical theory was itself thought from the interiority of logics.” This obviously changed in the later development of his position. Alain Badiou, 
a condition and that the whole perspective of Being and Event provides a meta-ontological, i.e. philosophical, re-formulation of what Badiou identifies as an eventally arisen truth (which transformed ontology). The key to understanding in what way the meta-ontological account of being relates to the meta-phenomenological one of appearing thus lies, what else could be expected, in the account of eventally emerging truths. This does not - and cannot - mean that there is a subject mediating the two distinct spheres of ontology and phenomenology. It rather means that from within a certain post-evental practice we become able to make and formalise the difference between being and appearance. This, therefore, does not necessarily mean that the appearance of being is an event and that such eventuality must be inscribed into our concept of being. Appearing as such is as unevental as being, even if the formal conceptualisations thereof are. But this also implies that the concept of being is not formulated within an objective ontology. It is itself part of a subjectivised truth-body that auto-dictates and regulates its own laws of appearance to itself. "Being" appears in ontology (as discourse) as it does in (philosophical) meta-ontology.

This is to say, 1. there is no path that leads from being to appearance: the concept of being as formalized after the Cantor and Cohen event in ontology is not generative of appearance. But these events changed something about the (transcendental regulation of the) appearance of ontology. There is, thus, 2. a path that leads from appearance to being, under the condition that there is appearance. The relation between being and appearance is a one-way street. Being and appearance look very different from the perspective of (meta-)ontology (as being is then just an immobile multiple of nothing and appearance is a form in which it is counted-as-one) and from that of the logics of appearance (where being is what appears and appearance is the variety in which it appears). In a conceptual sense, this means that there is no (reciprocal or deductive) relation between being and appearing. Thereby, the appearance of being is non-deriv-

"Préface de la nouvelle édition", in Le concept de modèle. Introduction à une épistémologie matérialiste des mathématiques, Fayard, Paris 2007, p. 30. 
able (nothing necessitates it) and hence contingent. ${ }^{50}$ Yet, when there is appearing, what appears is being (even when formalised within ontology). ${ }^{51}$

If there is no derivable relation between being and appearing, does this mean that - this may almost sound reminiscent of Kantian problems ${ }^{52}$ - the third volume is supposed to provide the systematic consistency with - and hence relation to - the previous two unrelated accounts? The project of The Immanence of Truths is not to conceive of truths from the standpoint of either being or appearing, but to begin with truth (even though, generally speaking, the structure of the book first deals with the ideology of finitude and then moves on to depict its infinite outside and thereby reverses the constitutional relation between the infinite and the finite, so that the infinite finally comes first - we thus get a repetition in miniature of Badiou's overall path in his last philosophical book). The third volume does not simply fill a gap left open. But it contributes to the ways in which we will have to re-read the previous two volumes. The third volume makes it unambitiously clear that primacy will have been given to the infinite (and thereby to truths) all along. To elucidate this claim, one could argue that the three volumes are linked with one another as the circles are within a Borromean knot: we have being (in its meta-ontological account), appearance (within its meta-phenomenological account), and the two respective accounts of the evental emergence of truth. Finally, we have an immanent account of truth, a conception of truth on and in its own terms.

50 Does this force us to assume that appearance is therefore necessarily constituted by that which is not-being-qua-being and hence the existence of appearance is itself the result of an event? If this were the case, what kind of event would we be talking about (since it seems rather difficult to account for it in terms of one of the conditions - note: it cannot be an event in ontology, because ontology is the "discourse on being qua being” (Badiou, Being and Event, p. 7), but this cannot mean that whatever takes place in this discourse could actually generate the appearance of being (where there was none before).

${ }_{51}$ One may see Badiou's claim that "[p]roblems of connection and continuity" - between $\mathrm{Be}$ ing and Event 1 and 2 - "do remain, namely between 'generic procedure' and 'intra-worldly consequences of the existence of an inexistent'” as pointing also to the problem I address above. Thus, I have formulated a possible solution and follow Badiou's remark that he "leave[s] them for another time, or for others to solve.” Badiou, Logics of Worlds, p. 39.

52 For a far more convincing reading, cf. Rado Riha, Kant in Lacan'scher Absicht: Die kopernikanische Wende und das Reale, Turia+Kant, Vienna 2018. It is important to note that whenever there is appearing, what appears is being, which means that we are not separated from being through appearing. 
But to speak of truth in and on its own terms, we have to introduce the concept of truth again, we have to say something about the truthness of truth. Badiou does this by means of the concept of the absolute, which as he claims was therefore "with us" ${ }_{3}$ all along - in the sense from Being and Event, 1 . We thus get the following schema, a Borromean knot with the (inexistent - I will return to this) absolute at its core:

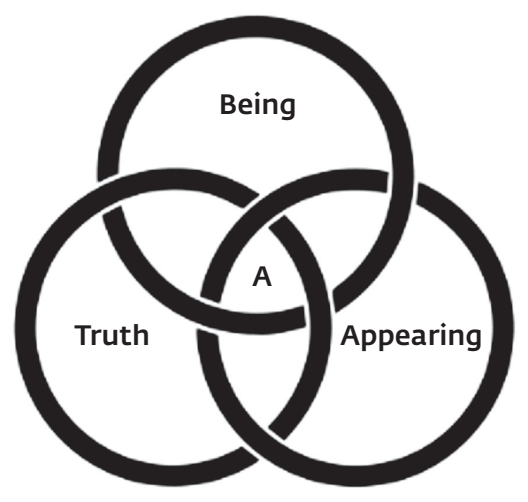

$A=$ Absolute

This model suggests, apparently, that each of the domains has an overlap with the others and hence a unique perspective on how to conceive of them. ${ }^{54}$ Only

53 Badiou, L'Immanence des vérités, p. 415 and cf. also Ruda, “Tovariši”. Here it is also interesting to note that with regard to the work Badiou did with(in) his seminar, he moves from: a) the logical theory of models (1980-1983) - already precipitated by his 1969 Concept of the Model; to b) (mathematical) set theory (1983-1989) - Being and Event is published in 1988; and then moves quickly through c) the (mathematical) theory of numbers (1989-1990) - Number and Numbers is the manifestation of this period; addresses d) the (mathematical) theory of categories, topos (1990-1996); and e) the philosophical theory of worlds (1996-2001); before finally dealing with f) the ideology of finitude (2001-2004); g) how to conceive of an exit therefrom (2004-2012); and ultimately h) deals with the immanence of truth (2012-2015).

54 To my mind, one could give a similar rendering of Hegel's philosophical system, with Nature, Spirit, and Logic as circles and, again, the absolute located at their intersection. I offered an interpretation of Hegel's Logic along the lines of The Immanence of Truths in Frank Ruda, “Hegel's Immanence of Truths”, in Badiou and German Philosophy, ed. by Jan Völker, Bloomsbury, London 2019, pp. 51-69. It might be interesting to discuss if one may read the above rendering as pointing out that the absolute is nothing but its own unfolding, its exposition. 
through their entanglement are we able to see that the absolute is always closeby. The three books form a Borromean knot of being, appearance, and truth: there is being, a being of truth, a being of appearance and an appearance of being, and an appearance of truth; there are truths of the presentations of being, of specific worlds - and, as we will see: the truth of an account of being if formulated in a condition of philosophy can lead us to formulate an absolute ontology (I will get to this). In order to keep these rings together, the absolute is needed and it only in-exists in this entanglement; it becomes conceivable in the margin(s) at the centre. It is the knot's off-side, out-side, out-of-sight, out-of-space, out-of-place, its hors-lieu..$^{55}$ One needs being, appearance, and truth to expose it.

Another way of putting this is the following: ontology is a condition and hence the site of potential truth procedures. Therefore, the determination of the being of a truth can itself be regarded as the (knowledge-) product of a truth-procedure. The absolute is what can be said to determine the truthness of truth. We can understand how to conceive of it by determining the consequences and implications of the truth procedure that allows for a new thought of the concept of being, by allowing for a new conception of infinity, and of its appearance as part of the truth-body that is unfolded within ontology in the aftermath of the (Cantor-event and) Cohen-event. This brings with it also a new conception of truth. We get an absolutely immanent account of the truthfulness of truth, of the absoluteness of truth if we take into account that ontology is itself a condition where something happened that philosophy has to incorporate. From this meta-ontological perspective, a truly novel ontological account of the being of infinity and thereby of truth must be read as a result of a truth procedure that has the peculiar features that it - qua result - also provides an immanent "measure" of its own truth-value. An ontological truth procedure produces a thinking of infinity that through the intervention of philosophy can be comprehended as providing an evaluation of a truth's truthness.

This does not lead us to the discovery of the one and only true truth. The absolute is not the truth. Rather, it is because of a truth-unfolding in (and as) ontology that we can forcefully imagine an absolute - and hence no longer historical ontology. An ontology that allows us to verify that the truth we are engaged in -

55 Badiou, Theory of the Subject, pp. 3-21. This is why Badiou will indicate that the absolute is not a multiple and not a set. 
sharing its ontological consequences - is actually true. Thereby it provides an immanent "measure" of itself and of all other potential truth procedures. A truth occurs in ontology in such a way that it creates a fiction of knowledge that allows us to determine the absoluteness, i.e. the truthness of the truth that created this very fiction. Badiou always insisted that "the potency of a truth depends on the hypothetical forcing. It consists in saying: 'If we suppose the generic infinity to a truth to be completed, then such or such piece of knowledge must be imperatively transformed." ${ }^{56}$

An absolute ontology must be an ontology whose very constitution is impacted and effectuated by a truth procedure, yet which is only properly constituted with the hypothetical formulation - i.e. with the necessary even though impossible and thus fictitious forced totalisation - of all possible effects of this very truth procedure. We create such fictitious totalisation in ontology and thereby we articulate an absolute measure of truthness, which implies that we formulate a complete, absolute, ontology. It is precisely in this sense that we surpass the "structural" and "historico-existential" ${ }^{57}$ determinations of truth and start to determine its proper truth character. In its unfolding, we bend the process back onto itself and totalise it.$^{58}$ Yet this totalisation is necessarily fictitious and, even though necessary, at the same time bears the mark of its own impossibility due to the fact that the consequences of a truth procedure are never just completed - otherwise, at least in an immediate understanding, a truth would be finite or limited..$^{59}$ Even though a truth procedure absolutises ${ }^{60}$ itself in ontology and thereby generates the concept of the absoluteness of truth, we must "think a truth as at the same time grasped in its immanence to the absolute and at its distance to this grasp." ${ }^{61}$ If we were to forget that the totalisation is a hypothetical fiction bridging the impossible, we would reduce truth to knowledge or make truths into one truth (and end up either suspending truth altogether or turn philosophy into religion). An absolute ontology is a necessary and impossible project of a philosophy that identifies ontology with mathematics, mathe-

\footnotetext{
56 Alain Badiou, “The Ethics of Truth: Construction and Potency”, in Pli 12 (2001), p. 252.

57 Badiou, L'Immanence des vérités, p. 20.

58 This sounds highly compatible with certain contemporary readings of Hegel. concept of the end into two. One divides into two: even at and in the end.

6o Badiou, L'Immanence des vérités, pp. $415 \mathrm{ff}$.

${ }^{61} \quad$ Ibid., p. 402.a
} 
matics with a specific thinking infinity (without one), and infinity (without one) as what allows for conceiving of truth: we must have a measure (of truths), we cannot have a measure, we will have a measure.

\section{Impossible, yet necessary: forcing absolute ontology}

The task is clear. The Immanence of Truths attempts to formulate what makes a truth truly, really true, so that it is ultimately not relative to the situation or world whose truth it is or in which it appears as truth. Even though truths are formed within (and with the material of) a world or situation, they must also be independent of it. Obviously, this demands a non-relative (non-situation specific, non-world specific), i.e. an absolute, take on truth. It necessitates an absolute ontology (of truth), which provides us with a kind of measure or orientational guideline for what is true (and for what might be truer than something else). If a truth is not relative, there must be a measure. And this measure cannot simply be timely and revisable, but it must be absolute. That is to say: to have a concept of truth one needs a concept of absoluteness, ${ }^{62}$ because if one overemphasises the idea that a truth is always situated and is a truth of this or that situation, one gives up the idea of truth and endorses that everything is externally determined and relative (to a situation or world and this was what remained in part unresolved by the first two volumes of Being and Event). What is at stake here thus also immanently links the concept of truth and that of freedom. If there were no such concept that allows one to immanently determine what truths are, they would also not be transmissible and therefore would not be as universal as they conceptually must be. One thus needs a specific kind of dialectical take on truths' truth and this is only offered by an immanent perspective. Walter Benjamin once remarked that "the inner [das Innere] of history is reserved for the dialectical gaze,"63 and if truths are what really makes history in all relevant senses of the term, the same holds for Badiou's project.

62 This even holds for the idea that there is no truth - since it, trivially, claims to be absolutely valid (and hence true). It is thus not that it is difficult to say something about truth (we do this all the time - and Hegel's Phenomenology shows us all possible ways in which we can be wrong about what we take to be true and how we attempt to avoid correcting ourselves), but it is difficult to confront what is true about truth. It is difficult because here we confront the infinite.

${ }_{63}$ Walter Benjamin, "Ein Jakobiner von heute. Zu Werner Hegemanns ,Das steinerne Berlin'”, in Gesammelte Schriften, Vol. 3, Suhrkamp, Frankfurt am Main 1991, p. 263. 
This necessitates that one creates the forced and forceful fiction of a totalisation, of an absolutisation of an active truth procedure in the condition of ontology. The result of this forcing is the idea of an absolute ontology. In The Immanence of Truths, $\mathrm{V}$ is the name of the result of such an operation of forcing. Yet, it is of importance to qualify that $\mathrm{V}$ is more than what makes a merely fictitious ${ }^{64}$ whole of a truth. Since the operation of forcing - i.e. a constitutive element of any truth procedure whatsoever ${ }^{65}$ - is what enables truths to have an effect on knowledge. Forcing compels new terms into knowledge and in the present case it forces a paradoxical fiction of a knowledge of truth into knowledge. ${ }^{66}$ It is here that we must emphasise the fictitious qualification of the forced concept of an absolute ontology: that it is fictitious means that we do not reduce and dissipate truth to and in knowledge. But we operate as if there were a knowledge of truth, a real science fiction of truth in the form of an absolute ontology. To reduce truth to knowledge is, on the other hand, what the constructability hypothesis (shorthand for: Gödel - "who constitutes the latent force of the ideology of finitude" since the publication of the first volume of Being and Event) is ultimately about.

In its third volume Badiou must make a strong case why the universe of absolute ontology, with the absolute as the place where all possible forms of being are placed (this idea being the result of the operation of forcing), must be different from the constructible universe. Otherwise, we would violate what Being and Event stated about the being of truths, namely their generic nature, bringing together elements that have nothing else in common than having been brought together. The danger lies in seeing in the result of ontological forcing an absolute validity

64 "Fiction" here does not mean that we are dealing with an illusory or merely fake being (of language or metaphysics only - cf. Badiou, L'Immanence des vérités, p. 22). Rather it means that truth (in its totality), in Lacan's phrasing, has the structure of a (necessary, yet impossible) fiction.

65 This is already the argument of Vol. 1. Cf. Badiou, Being and Event, pp. 391-440.

66 In precisely this sense, Badiou speaks of "an - almost true - knowledge of what can be, grasped in its proper advent, the almost absolute being of truths." Badiou, L'Immanence des vérités, p. 393.

${ }^{67}$ Ibid., 246. "Gödel” stands for a specific kind of problem - since he does not simply defend a formalist interpretation of mathematics, wherein mathematics is understood as a (language) game, but is a "convinced Platonist" (ibid., p. 67). There is thus a struggle within the Platonic conception of mathematics - one (philosophical Platonism) divides into two (constructivism and genericism). That is to say: Gödel also absolutises, but the outcome is quite different, namely he stands for "the possibility of an integral absolutisation of finitude.” Ibid., p. 257. 
of the constructible universe - or in Badiou's rendering, in assuming " $\mathrm{V}=\mathrm{L}$ "68, which describes "the victory of what is (constructible) over what is not" and is ultimately "realist' propaganda." "' Against the assumption that "all that is, is constructible," which is the foundational axiom of "the ontology of finitude," it is crucial not to misconceive the forced totalisation of an immanently untotalisable ontological truth procedure in a finitising way. This is what is at stake with the concept of absolute ontology.

Forced ontological totalisation must be non-constructible. It can neither lead to "das Seiende im Ganzen," to "beings as a whole" 71 in Heidegger's sense - as there is no existing whole in set theory - nor can and should we assume that by means of forcing we would find a structural paradigm that enables us to imagine how the absolute - of an absolute ontology - actually exists. This is the fundamental problem with Cantor's continuum's hypothesis, since it assumes that the relation between different sizes of infinity (more adequately: between the size of the infinite set of natural numbers and the size of the larger infinite set of real numbers) could be constructed by applying the successive ordering structure of the set of natural numbers. Then their relation could be described by recourse to the structure of natural numbers. ${ }^{72}$ The problem with this, as with "whole numbers," which "have become the alpha and omega of each evaluation when it comes to ideas [...] or of the value of historical experience,"73 is that this finitises infinity by assuming there is a constructible structure. The domain of infinity is thereby turned into a domain where there is more of the same (finitude). One therefore must create an impossible yet necessary forced totalisation of what is non-totalisable, i.e. one must create an absolute ontology within which one also forcefully wards off the temptation of constructability.

68 Ibid., p. 247. "L" stands for the constructible universe and V for the formalisation of "the Vacuum, the great void, but also the Truths." Ibid., p. 40.

69 Ibid., p. 247.

$70 \quad$ Ibid., p. 441.

${ }^{71}$ Martin Heidegger, What is Metaphysics? Original Version ed. by Dieter Thomä, in Philosophy Today, 62, (3/2018), p. 738.

72 One problem with this is that it does not allow us to see that when we attempt to say something about infinity, we actually do not know what we are talking about. This becomes even more problematic for Badiou when we use the concept of "infinity" without knowing anything about what happened in mathematics in the last fifty years. Cf. Alain Badiou, In Praise of Mathematics, Polity Press, London 2016, p. 43 f.

73 Badiou, L'Immanence des vérités, p. 444. 
If this cannot be done, our attempts are wasted; if we can, there might be an oeuvre. The task is to first provide an outline of such a forced absolute ontology and then to delineate the conditions under which it remains non-constructible. And this is what The Immanence of Truths does, inter alia, by positing that " $\mathrm{V}$ is not, itself, a set" and that it has the "capacity to welcome infinitely many infinite forms of possible-being." Even though it presupposes "a kind of ultra-infinity,"74 this should not lead us to the assumption that an absolute ontology implies an ontology of the absolute. The absolute is the place of all possible forms of being, yet this place does not exist: it is and must be inconsistent. ${ }^{75}$ It inexists and hence forcing an absolut(ised) ontology - i.e. "the possible anticipation of a real phenomenon" ${ }^{76}$ - does not ontologise the absolute. ${ }^{77}$ The absolute is rather the real of truth(s).

\section{Dialectics of axioms}

Almost at its beginning, The Immanence of Truths formulates an absolute ontology - and it argues that set theory fulfils all criteria to be such an ontology. An absolute ontology is "the existence of a universe of reference, a place of thinking being qua being" ${ }^{78}$ that has four defining features. The first of its features is that "it is immobile." This means that being as such does not have a history which is itself, more or less obviously, an implication of the term "absolute ontology." Being does not have a history because being does not move. It provides the background against which one can conceive of movement and history, but neither is it an internal attribute of being as such. For an absolute ontology, being is unmoved - and this implies that even the mathematical formalisation of movement itself is articulated somewhere, where there is no movement: "the

74 Ibid., p. 370. Also instructive here is W. Hugh Woodin, “The Realm of the Infinite”, in Infinity: New Research Frontiers, ed. by Michael Heller and W. Hugh Woodin, Cambridge University Press, New York 2011, pp. 89-118.

75 In this sense, this operation of ontological forcing remains faithful to Cantor, who "does not step back from associating the absolute [absoluité] and inconsistency.” Badiou, Being and Event, p. 41.

76 Badiou, L'Immanence des vérités, p. 41.

77 Badiou therefore repeatedly insists that $\mathrm{V}$ is not a multiple (not a set) and hence is truly inconsistent within the universe in which it is formulated.

${ }_{78}$ Badiou, L'Immanence des vérités, p. 36. 
mathematical equation that formalizes the thinking of movement has no specific location, except, in fact its mathematical absoluteness."79

Being is, secondly, intelligible in all its dimensions on the basis of nothing. This implies that we do not have to refer to any kind of substance (or positive properties), nor to a subject to conceive of being qua being. ${ }^{80}$ The only thing we need is no-thing. We need (substanceless) nothing - a nothing without nothingness - to unfold this ontology consistently - which obviously is always an advantage in comparison to needing something. Being is composed of nothing and nothing does not move: there is nothing in the grand void which composes being. ${ }^{81}$ This means that being is not composed i.e. it is "non-atomic." 82 Thirdly, being can only be thought by means of the "axioms to which it corresponds." ${ }_{3}$ This allows us to distinguish an absolute ontology from all kinds of phenomenology (being cannot be experienced) and all types of empiricism - being is not empirical (but constructed by axioms on the basis of nothing). This is crucial, since thinking being is independent of the fact whether it is or is not. In an absolute ontology, thinking and being are the same when we are thinking being. The final and fourth feature of the absolute ontology is that it obeys a principle of maximality, namely that "any intellectual entity whose existence can be inferred without contradiction from the axioms that prescribe it, exists by that very fact." ${ }^{84}$ What is rational is real, what is real is rational. That is to say, any "thing", any being, that can be derived from the axioms of the absolute ontology alone is taken to exist because it can be inferred without contradiction. The four principles relate to one another dialectically. There is a dialectic of the axioms of absolute ontology: ${ }^{85}$

79 Badiou, In Praise of Mathematics, p. 75.

so Badiou gives the following example: "Take a revolutionary movement, an uprising that will become historic, such as the storming of the Bastille, let's say. Considered in terms of its pure political value, as a symbol, a reference point, an absolute beginning of a process, this event cannot be broken down into separate units. It's not the result of an addition of factors.” Ibid., p. $75 f$.

${ }_{81}$ Here it is interesting to consider the beginning of Hegel's Logic which Badiou commented on in similar terms in Alain Badiou, The Rational Kernel of the Hegelian Dialectic, re.press, Melbourne 2011; cf. also Rebecca Comay and Frank Ruda, The Dash - The Other Side of Absolute Knowing, MIT Press, Cambridge, 2018, pp. 87-106.

82 Badiou, L'Immanence des vérités. p. 36.

83 Ibid., p. 37.

84 Ibid.

85 In what follows I recapitulate a public discussion with Alain Badiou (and Jan Völker) on the concept of absolute ontology. Cf. the recording at: https://vimeo.com/28417395. 
Beginning with and within an immobile place (i.e. "V"), which is entirely static, the thought of being does not introduce any kind of movement into it $\left(1^{\text {st }}\right.$ feature). How must this place be conceived to be really immobile? There must be no-thing in it, there must be a pure nothing-ness "in" it ( $2^{\text {nd }}$ feature). The place where we think being is absolutely empty and hence entirely immobile. Only such nothing(-ness, even though the substantialising postfix is misleading) is immobile, since every-thing, certainly any (concrete) thing moves and is in transformation all the time. From the first principle - being is entirely immobile we are thus necessarily led to assume that an absolute ontology commences in (and with) nothing(-ness). This forces us to consider how we are able to think this nothingness - since it obviously can neither be empirically experienced nor can we simply deduce it from a given preceding concept. There is one possibility of how to think it as such, notably by recourse to principles or axioms ( $3^{\text {rd }}$ feature). Axioms represent a set of theoretical affirmations needed to realise and comply with the first two features of an absolute ontology. The affirmative positing of axioms is thus a consequence of the $2^{\text {nd }}$ feature, which is a dialectical consequence of the 1st feature. The principle of maximality can now also be regarded as a dialectical consequence of the $3^{\text {rd }}$ feature, because if you think on the basis of axioms, you must admit all of their consequences to really think in accordance with them. This is to say, the decision that being is immobile is what leads us to the set of features by means of which an absolute ontology is unfolded. Set theory fulfils all these criteria and thereby becomes the paradigmatic candidate for an absolute ontology.

As a consequence of a truth procedure taking place in ontology, we can force an absolute ontology that we then meta-ontologically identify with the very discourse on being that we (already had) identified as ontology. ${ }^{86}$ The results of ontological forcing are also registered in a meta-ontological manner and affect the conception philosophy has of its ontological condition. It affects meta-ontology. The formulated absolute ontology debunks - different from Spinoza, who for Badiou was the first to claim that "a consequent materialism demands an

86 I named this operation - an operation which can happen under the specific historic condition that the very existence of conditions, i.e. of truths as such, is threatened - philosophical forcing and have shown in what way it is linked to what psychoanalysis calls "working through”, in Frank Ruda, For Badiou. Idealism without Idealism, Northwestern University Press, Evanston 2015, pp. $127 \mathrm{ff}$. 
absolute referent" ${ }^{87}$ - all substantial, i.e. unifying and one-ifying, properties of substance. It is important that $\mathrm{V}$ does not exist and incoheres, since thereby it also avoids introducing substantial attributes of an already given subject (and eliminates all substantial links between the two, too). It is important that such non-substantial absolute ontology is absolute, but not objective. It is not an objective ontology because it does not give a description of any kind of object nor any objective account. But this does not make it relative or relativist. Yet, here we encounter a peculiar almost Kantian question (slightly resonant of debates around his table of categories): is this set of axioms of absolute ontology complete or not? If it were not complete, it may be accidentally incomplete - and then nothing would change with regard to the status of this ontology - or it may be systemically incomplete - and this would change its absolute character. To avoid jeopardising the absoluteness of ontology, Badiou insists that the set of axioms can be completely determined, even though it has not yet been entirely discovered.

\section{Truths "in" the absolute: forced freedom and necessary totalisation}

Thus far, I have reconstructed Badiou's claim that ontology is a condition of philosophy and that this implies that there can be truth procedures taking place within it. The specificity of this type of truth procedure lies in the fact that it unfolds the potential of scientific discoveries within the field of mathematics and that this unfolding - in its retroactive and creative dimension ${ }^{88}$ - leads to a theorisation of different types of infinity, which in turn can itself be read as offering a conceptualisation of the truthness of truths. This finally allows us to apply its conceptualisation of truths as part of the unfolding of a truth procedure taking place in ontology onto the very concrete procedure that formulates this concept of truth. There is a torsion of the ontological truth procedure. This means that the very truth-conceptualisation which it allows by means of theorising different sizes of infinity applies to itself and thereby it allows for an absolute - in the sense of being fully detached from everything but itself - and a fully immanent "measuring" of its own truth (i.e. infinity) by means of its own creation. We get a true theory of truths - which evaluates truth solely from within its own imma-

\footnotetext{
87 Badiou, L’Immanence des vérités, p. 37.

88 Ibid., p. 588ff.
} 
nent practical unfolding. This theory of truth is practically self-absolutising. ${ }^{89}$ The further we force this immanent and absolute self-measurement, the more we are forced to formulate the idea of an absolute ontology ${ }^{90}$ - something that philosophy articulates so that this idea will prove compossible with contemporary creations in other conditions of philosophy, allowing us, for example, to philosophically identify a truth in politics. The self-absolutisation here chimes with philosophy's “desire for truth."

What has been missing from the argument thus far is how the dialectically interconnected axioms of absolute ontology relate to the conceptualisation of the different sizes of infinities. This move, in all its demanding mathematical intricacy, leads Badiou to undertake in The Immanence of Truths a veritable and majestic renewal of the dialectics of quantity and quality, a dialectics of quantity and quality exploding in all directions - creating the absolute place "V", which can be imagined to be structured similar to the letter that names it. ${ }^{22}$ This move into the mathematical discussion of infinity is crucial since only with this step do we complete the torsion, the peculiar circle, and only thereby see how we can force mathematics into the status of an absolute ontology (even though the latter is a meta-ontological concept). We only get a proper absolute ontology that provides us with a real conceptualisation of truths if we explore the domain of infinity, the powderiness of V. This is why two - at least - further clarifications are needed concerning the previous remarks:

First, an absolute ontology must reject the Continuum Hypothesis - as it would impose a structural model for the relations between different sizes of infinity and thereby the realm of infinities would be made constructible and finite. ${ }^{93}$ This

89 Badiou identifies this move that happened "in the last twenty years" with the work of Woodin. Cf. Badiou, L'Immanence des vérités, p. 68f. For reasons that would explode the length of the present article, I cannot elaborate why this move is justified and yet cannot be repeated, such that after establishing an absolute ontology it is truly absolute. The reason for this is elaborated in Badiou, L'Immanence des vérités, p. $495 \mathrm{ff}$. I will return to this elsewhere.

90 Which is the reason why the absolute must be in a strict identity with itself: ibid., p. 451f.

91 Badiou, "L'entretien de Bruxelles", p. 91.

92 Cf. schema 2 in Badiou, L'Immanence des vérités, p. 688f. One can read this as Badiou's take on the famous "parallelism" argument in Spinoza.

93 Which is why Badiou takes it to be false, even though it is compatible with the axioms of pure set theory, cf. Badiou, L'Immanence des vérités, p. 310. 
must mean that we simply cannot derive and deduce the infinite from finite succession. To overcome the finitising constructivist orientation, we must disentangle thinking the infinite from "the false infinity of hopeless successions." 94 This false succession is false because it has three problematic implications: 1 . we have a succession that follows one steady model whereby any infinite set is followed by a greater infinite set and the relation between the two is always of the same kind (which is constructible in advance). But the infinite can only be properly thought if we unbind it from any link to the one and do not problematically generalise the move by means of which we can get from one infinity to a larger one (otherwise we would in advance unify, make consistent, and count as one all these transitions). There is neither a largest one nor is there any one-structure by means of which we could construct all relations between infinite sets. 2 . this succession is false because with each new and larger infinite set, it would happen that we simply finitise the previous set. That is why we are tempted to encounter only potential infinity in the realm of natural numbers, at least if our concept of infinity emerges from the idea of stable succession. 3. It is false because it is a paradigm of what Hegel called bad infinity, since it continues endlessly - and this internal endlessness is precisely the ruse of potential infinity. In order to formalise actual truth, there must be actual infinity. We would not get an immanent measurement of truth if we simply followed an infinite succession of infinities nor an absolute ontology.

Second clarification: it is here that a choice needs to be made: "a crucial choice,"95 which Badiou identifies with the "fictitious opposition Cohen / Gödel." ${ }^{96}$ Either everything is constructible and hence finite (Gödel), a position that does not necessitate any choice at all, or there is a choice, a choice for which we have no criteria other than what we can anticipate will follow from opting for one or the other side. A choice which in this sense is determined by the fictitious anticipation of what it entails and which is constructed from a meta-ontological perspective. Philosophy here becomes an imitator and mimics a feature of the forcing-operation happening in its condition(s). If there is such a choice,

\footnotetext{
94 Alain Badiou, “Toward a New Thinking of the Absolute”, in Crisis and Critique, Special Issue, 1, (2/2014), p. 21.

95 Badiou, L'Immanence des vérités, p. 257.

96 Ibid., p. 266.
} 
philosophical forcing constructs a fundamental fictitious incompatibility: ${ }^{97}$ two sides that are so infinitely different that each amounts to an entirely different orientation with a whole range of implications (from consequences for the existence or inexistence of absolute truths, to what kind of ontology one defends and political positions one finds defensible, say if one's ontology is compatible with present regimes of domination or not, etc.). The infinite gap that we encounter between the finitising orientation of constructability and its finitised, only potential infinite, and the actual infinite of genericism with its "infinite potentiality," ${ }^{98}$ on the other side, forces us to choose. We here, through a forced philosophical fiction, surprisingly experience infinity, namely the infinity that separates the two sides of the choice. We experience the infinite when we identify the fictitious choice as a real choice, as one that forces us to be free and we cannot not choose. But we only encounter it if we construct the choice as choice and see that we must choose; otherwise, we have already chosen (constructability). ${ }^{99}$ And if we identify it as choice, we also have already chosen, since then we see that the constructible orientation absolutises de-absolutisation, i.e. it absolutises finitude, and this contradiction cannot but be a reactive (or obscure) defence mechanism against some truth taking place. If something truly happened in ontology with Cohen, its anticipated consequences absolutise ontology and this forces philosophy to create the fiction of a choice, which has already been made. With an ontological truth procedure there originates the fiction of an absolute ontology and philosophy is itself forced to force a fiction. Philosophy is meta-forced, forced to force the fiction of a choice whose only criterion lies in its anticipated consequences for ontology - which adds another layer of forcing. When we identify the choice as a choice, the choice has immediately been taken, it never existed as a matter of deliberation. This is the experience of freedom that The Immanence of Truths transmits. A freedom of and in thought, the free-

97 That it is a forced philosophical fiction becomes manifest in the fact that this choice does not seem to be a necessary choice at all for the mathematician - but for the philosophically informed, to put it neutrally, mathematician or for the mathematically informed philosopher it cannot but be one (for Badiou). Ibid., p. 223.

Max Horkheimer once remarked in a radio conversation that Sartre believed that people no longer decide. He added critically, and in line with the above, that the true problem is rather that they do decide but are not aware of it. Opting for Gödel is a spontaneous ideology that one barely notices as such. 
dom of a forced choice that we do not (as individuals) arbitrarily decide (according to our preferences), but that is decided within the immanence of thought.

But it is important to note that both sides are equally valid: both are compatible with set theoretical mathematics, ${ }^{100}$ even though its ontological status changes quite drastically if we opt for the one or for the other. This choice confronts us with freedom as we have no objective reasons to choose the one or the other; there is no normative grounding whatsoever apart from the anticipation of consequences and if we see what is at stake with the choice - if we understand the choice as choice - ultimately there is no choice, as there is only one option to choose when we anticipate what the consequences will have been. Between equal rights, forcing decides. As any choice, this choice is a real choice because it is structurally undecidable and this also means that it is already decided when we identify the choice as choice. What we have at our disposal is only the anticipation of what results from choosing either side. This anticipation is what Badiou calls “idea." ${ }^{101}$

The philosophical thinking of what was thought in its ontological condition manifests in the fictitious construction of a choice. This fiction of choice is forceful, since as long as one starts to see it, one can no longer choose to escape it and therewith one has already chosen - philosophy reminds us of what we were unaware we knew before. It is a choice of one's way of thinking that may manifest a "non-constructible subjectivity." 102 By being forced to choose one experiences freedom, since one experiences something of the infinite in identifying the infinite abyss that separates thinking under the guidance of an idea from the ideology of finitude. Freedom in thought exists only in the fictitious realm of a forced choice that has consequences in and for everything. This fiction provides us not only with a genuine experience of freedom in thinking - or in spirit, as one could say with Hegel, or more precisely: with a genuine experience of free-

100 Which is why, as Badiou points out, mathematicians as such would not come across this choice, since both positions are compatible with the delineated set theoretical universe.

101 Badiou, L'Immanence des vérités, p. 265. This is the treatment of a point - in the terminology of Logics of Worlds - I elaborated above. It should be clear why this shatters the predominant conceptions of freedom. I tried to make an argument pointing in this direction in Frank Ruda, Abolishing Freedom. A Plea for a Contemporary Use of Fatalism, Nebraska University Press, Lincoln 2016.

102 Badiou, L'Immanence des vérités, p. 265. 
dom in absolute spirit. If there are real differences at stake in this constitutive choice - and the subsequent development of the mathematics of different types of infinity will essentially develop these in different ways - this proves that there are some things one can only do within the realm of thought (and not in the same way in concrete life ${ }^{103}$ ). But thereby we may get a "new idea of human action," ${ }^{104}$ of thought and of truth. This forced freedom touches the absolute through the infinite gap separating the sides. In the absolute spirit of meta-ontology's constitutive choice there is an experience of freedom and of truth, since it is an experience of infinity ${ }^{105}$ - an experience that is transmissible under the condition that the fiction of this choice is transmissible.

The status of an absolute ontology is thus linked to an experience of freedom. It therefore does not come as a surprise that Badiou endorses that the absolute ontology (set theory) must also entail the axiom of choice. This axiom is only relevant for infinite sets and indicates that from any given infinite set, a set can be extracted that is composed of an element of each set that is an element of the original set - yet it does not offer any means to construct it. The axiom of choice indicates that there is a choice but it leaves open the criteria and framework of this very choice. When relating this back to the four features of an absolute ontology, this implies that the latter is fundamentally based on an essentially indeterminate choice: a choice that does not have any objective or subjective or concrete conditions, a choice that is determined by nothing, a pure (indeterminate) choice, a lawless choice. "It validates a choice whose norm does not pre-exist, a representation whose Law is unknown." ${ }^{106}$ The axiom of choice is an inner-mathematical dialectical consequence of the pure and lawless choice between constructability and genericism - on which the very inexistent existence of an absolute ontology relies - which takes axiomatic form. It repeats something of the immediate choice (conditioned by the torsion of ontology), yet in a different form. It is - in Hegelian terminology - a repetition of the immediate

${ }_{103}$ But the former fundamentally changes our effective - ontological, etc. - take on the latter. It means that we get a different concept of what thinking (and freedom) is. And we get it in thought and this can change everything. This was what Hegel argued for when he emphasised the non-practical nature of philosophy (in absolute spirit). And should not an absolute ontology be part of absolute spirit?

104 Jean-Paul Sartre, Search for a Method, Knopf, New York 1963, p. 45.

105 Which again proves the old point that truth can only be accessed in a one-sided manner.

106 Badiou, “Toward”, p. 20. 
as result, but, and this is crucial, now the pure choice repeats not at the ground and foundation of absolute ontology but in the literal heights of its development, namely in the theory of different sizes of infinity. An absolute ontology is framed by freedom at its ground - the forced choice to unfold the consequence of an event - and peak, the meta-forcical impact that the forced self-absolutising of ontology has for the very concept of meta-ontology. A freedom that is not a given unless we identify the choice as a choice and are thus forced to make it actual, because we have already done so.

\section{(Too) brief addendum on the end of infinity}

Based on a given infinite set, one can easily construct a new sort of infinity by means of what is called orthogonal operation. ${ }^{107}$ To do so, we measure it and determine its size, i.e. the number of its elements. This holds if the set is finite or infinite. If we call "Hans" the given infinite set - provided that we have managed to measure it - we can attempt to determine a set that is so incomparably larger than "Hans" that there are at least "Hans" many infinite sets that are smaller than it. So, we have a set, let us call it "Super-Hans" in comparison to which "Hans" is small, since there are "Hans" many infinite sets that are all smaller than "Super-Hans". "Super-Hans" comprises "Hans" times "Hans"sized sets. It is "Hans" Hans-times. If "Hans" is infinite, "Super-Hans" is clearly super-infinite. The problem that occurs within this type of construction of infinite sets is that retroactively the previous infinite set is finitised. "Super-Hans" finitises "Hans". If this were the case, we would only in appearance be dealing with infinite sets - until they are superseded and then they are finite again. We would thus end up again with a bad infinite and with a potential invalidation of everything we held to be true (if this is what we are talking about when we talk about the infinite).

In The Immanence of Truths, Badiou mobilises an astounding theorem that was developed in 1971 by Kenneth Kunen. It elaborates a meta-ontological precondition for conceiving of actual infinity (and hence truths). To cut this down violently: it proves that "numerical openness is not the law of infinity" and that there is no endless succession. The only way we encounter actual and true in-

${ }_{107}$ I am taking this elaboration from Alain Badiou, “Toward a New Thinking of the Absolute" (manuscript). All subsequent quotes are from this paper. 
finity therefore is, so to speak, by ending it somewhere. There is unwilling finitisation - in the idea of potentially infinite and eternal succession - and there is a different type of finitisation. The introduction of a limit, a region where the endless "process of the resorption of successive infinities" comes to an end. A bad infinite and - emphasising its Platonic undertones - a good infinite. There is no actual infinity without this peculiar type of end. Once the end of history was proclaimed as a precondition for an adequate concept of history, which implies that the resurgence of history will necessarily end and revolutionise what we conceive as history, and the end of art was proclaimed to be preparation for the emergence of a new art that will thoroughly shake what we previously deemed possible to be art. This was always different from the endless blabber about the end of (political history in democracy or art in art-theory, and of) philosophy, which Badiou has been heroically combatting for decades now. In the end, what the thinking of actual infinity ontologically and meta-ontologically necessitates is an emancipatory theory of the end. Only then can an actual infinity be thought that measures up to the infinity of the forced freedom at its origin. It might not be accidental that The Immanence of Truths represents the end of Badiou's philosophical enterprise.

\section{References}

Badiou, Alain, "The Ethics of Truth: Construction and Potency", in Pli 12 (2001), pp. 247-255

- "Beyond Formalization. An Interview", in Angelaki. Journal of the Theoretical Humanities, 8 (2/2003), pp. 111-133

- Le concept de modèle. Introduction à une épistémologie matérialiste des mathématiques, Fayard, Paris 2007

- Theory of the Subject, trans. B. Bosteels, Continuum, London/New York 2009

- Logics of Worlds, Being and Event, 2, trans. A. Toscano, Continuum, London / New York 2009

- Le fini et l'infini, Bayard Culture, Paris 2010

- “Conférence de Ljubljana”, in Filozofski Vestnik, 32 (2/2012), pp. 7-24

- “Dix-neuf réponses à beaucoup plus d'objections", in Entretien 1. 1981-1996, Nous, Paris 2011, pp. 59-80

- "L'entretien de Bruxelles", in Entretien, pp. 81-110

- "Philosophie \& Politique", in Entretiens, pp. 125-140

- "L'être en nombres", in Entretien, pp. 167-196

- The Rational Kernel of the Hegelian Dialectic, re.press, Melbourne 2011 
- Being and Event, trans. O. Feltham, Bloomsbury, London / New York 2013

- Le séminaire - Images du temps présent: 2001-2004, Fayard,Paris 2014

- "Toward a New Thinking of the Absolute", in Crisis and Critique, Special Issue, 1 (2/2014), pp. 19-24

- In Praise of Mathematics, trans. S. Spitzer, Polity Press, London 2016

- Le séminaire - L’un: Descartes, Platon, Kant (1983-1984), Fayard, Paris 2016

- L'Immanence des vérités. L'être et l'événement, 3, Fayard, Paris 2018

- Can Politics Be Thought?, trans. B. Bosteels, Duke University Press, Durham / London 2019

Benjamin, Walter, “Ein Jakobiner von heute. Zu Werner Hegemanns ,Das steinerne Berlin”, in Gesammelte Schriften, Vol. 3, Suhrkamp, Frankfurt am Main 1991, pp. 260-265

Comay, Rebecca and Ruda, Frank, The Dash - The Other Side of Absolute Knowing, MIT Press, Cambridge 2018

Hegel, G. W. F., Science of Logic, trans. G. Di Giovanni, Cambridge University Press, Cambridge 2010

Nagel, Thomas, “What Is It Like to Be a Bat?”, in The Philosophical Review, 83 (4/1974), pp. 435-450

- A View from Nowhere, Oxford University Press, Oxford 1986

Riha, Rado, Kant in Lacan'scher Absicht: Die kopernikanische Wende und das Reale, Turia+Kant, Vienna 2018

Ruda, Frank, For Badiou. Idealism without Idealism, Northwestern University Press, Evanston

- Abolishing Freedom. A Plea for a Contemporary Use of Fatalism, Nebraska University Press, Lincoln 2016

- “Hegel’s Immanence of Truths”, in Badiou and German Philosophy, ed. by Jan Völker, London, Bloomsbury, 2019, pp. 51-69

- “Tovariši absoluta, ali: Kje je “auprès de nous?””, in Problemi, (3-4/2019), pp. 133-150

Sartre, Jean-Paul, Search for a Method, trans. H.E. Barnes, Knopf, New York 1963

Woodin, W. Hugh, “The Realm of the Infinite”, in Infinity: New Research Frontiers, ed. by Michael Heller and W. Hugh Woodin, Cambridge University Press, New York 2011, pp. 89-118

Žižek, Slavoj, Ruda, Frank, Hamza, Agon, Reading Marx, Polity Press, London 2018 